\title{
educação

\section{O mito da ausência de preconceito racial na educação infantil no Brasil}

\author{
Circe Mara Marques \\ Universidade Alto Vale do Rio do Peixe e \\ Universidade Comunitária da Região de Chapecó, \\ Brasil \\ LENI VieIRA DORnelles ${ }^{I I}$ \\ Universidade Federal do Rio Grande do Sul, Brasil
}

Este artigo trata do preconceito racial na Educação Infantil. Resultou de uma pesquisa qualitativa, realizada em escolas infantis da região metropolitana de Porto Alegre, em 2013. Teve o propósito de investigar o modo como as culturas africanas são apresentadas às crianças de 0-3 anos no sentido de implantar o Art. $7^{\circ}$, inciso V, das Diretrizes Curriculares Nacionais para a Educação Infantil (DCNEI). Segundo esse documento, as propostas pedagógicas devem estar comprometidas com o rompimento das relações de dominação diversas, inclusive étnico-racial. A coleta de dados ocorreu através de observações e conversas com gestores e professores que atuam em escolas infantis. Os resultados mostraram que a maioria dos profissionais desconhece as DCNEI. Estes afirmaram que não ocorrem problemas raciais na Educação Infantil e justificaram que as crianças de 0-3 anos são pequenas e não percebem tais diferenças. Praticamente, não há materiais didáticos e imagens de pessoas negras nos espaços das escolas pesquisadas. É preciso não só dar visibilidade às crianças de 0-3 anos como também desconstruir o mito da ausência de preconceito racial para que as histórias e culturas africanas adentrem nos tempos e espaços destas escolas.

Palavras-chave: Educação Infantil; Diretrizes Curriculares Nacionais para a Educação Infantil; Preconceito racial

\section{O PRETEXTO DESTE ESTUDO}

De acordo com os dados divulgados em 2016 pelo Instituto Brasileiro de Geografia e Estatística (IBGE), 8,2\% dos brasileiros identificaram sua cor ou "raça" como preta, $44,2 \%$ como parda e $47,7 \%$ como branca. Para efeitos estatísticos, o IBGE classifica como população negra a soma dos pretos e pardos.
Assim, as pessoas negras e pardas representam $52,4 \%$ da população brasileira. Contudo, é necessário prudência ao analisar esses dados, considerando a histórica tendência ao branqueamento que se observa nas classificações raciais feitas no Brasil, de modo que esse percentual pode ser ainda maior.

Estudo do Programa das Nações Unidas para o Desenvolvimento (PNUD) - órgão da ONU 
- em parceria com a Fundação João Pinheiro e o Instituto de Pesquisa Econômica Aplicada (IPEA) mostra, no Índice de Desenvolvimento Humano (IDH) da população negra no Brasil, que esta tem uma década de desvantagem em relação à população branca. Ou seja, a qualidade de vida das famílias negras é inferior à das famílias brancas ao tratar-se da saúde, alimentação, educação, habitação, renda, lazer, etc. Tal panorama "coloca em xeque o mito da democracia racial" supostamente vivido na sociedade brasileira (Gomes, 2012, p. 731), mais ainda, no caso desta pesquisa, o mito de ausência de preconceito racial em muitos níveis da educação das crianças. As relações raciais estão imbricadas em relações de poder. A partir de Foucault (1987), poder é uma prática social constituída historicamente e que intervém materialmente, atingindo a realidade mais concreta dos indivíduos, ou seja, o seu corpo (Foucault, 1987).

Hall (2003) explica que "raçaéuma construção política e social. É a categoria discursiva em torno da qual se organiza um sistema de poder socioeconômico, de exploração e exclusão ou seja - o racismo" (p. 69). Nesse sentido, considera-se que racismo não é natural, ou seja, ninguém nasce com propensão a discriminar o outro, embora sejam recorrentes os discursos que buscam "justificar as diferenças sociais e culturais que legitimam a exclusão racial em termos de distinções genéticas e biológicas, isto é, na natureza" (Hall, 2003, p. 69).

A discriminação racial existe e persiste em diferentes segmentos da sociedade brasileira. Ela foi historicamente produzida e disseminada a partir desses discursos que circulam repetidamente nos clubes, nos livros, nos jornais, na televisão, no cinema, nos brinquedos, nas escolas, etc., de modo que os saberes das crianças brasileiras sobre ser negro constituem-se a partir de suas experiências nos distintos espaços com seus pares, sejam eles adultos ou crianças (Dias, 2012).

A escola não pode restringir-se a ensinar conteúdos desvinculados da realidade social e cultural das crianças, embora muitos educadores ainda acreditem que discutir questões raciais seja função "dos militantes políticos, dos sociólogos e antropólogos" (Gomes, 2005, p. 146). Não podemos esquecer que as crianças e suas infâncias fazem parte desse mundo de relações. Para Sarmento (2005), a infância é socialmente construída e compõe-se a partir de um estatuto social, com variações demográficas, econômicas, políticas, culturais e práticas sociais em um processo de contínuas modificações. As questões raciais que atravessam as infâncias fazem parte da formação humana (Gomes, 2005) e é tarefa da escola não somente discuti-las, mas inventar outros modos de se relacionar com as diferenças, inventar pedagogias antirracistas. Certamente um dos grandes desafios da educação do século XXI é problematizar as relações de poder e produzir estratégias para interromper os discursos que se fundam na suposta superioridade de uns em detrimento de outros.

Ao estudarmos as questões raciais e a implementação de documentos que as normatizam, não queremos dizer que estas dariam conta de uma educação antirracista. Tentamos entender como tais documentos estão sendo implementados na educação das crianças, buscando rastrear continuidades obscuras por seu próprio imediatismo e determinar os processos de montagem das peças mestras, seus engates, suas maquinarias forjadas. Questionamos para que servem e a quem, a que sistemas de poder estão ligados, como se transformam e se disfarçam no cotidiano escolar, desde a Educação Infantil.

A Constituição da República Federativa do Brasil (CFB/1988), a Lei n. ${ }^{\circ} 8.069 / 1990$, que dispõe sobre a proteção integral à criança 
e ao adolescente, o Estatuto da Criança e do Adolescente (ECA), a Lei n. ${ }^{\circ}$ 9.394/96, que estabelece as Diretrizes e Bases da Educação Nacional (LDBEN), e a Lei.$^{\circ}$ 10.639/2003, que inclui no currículo oficial da Rede de Ensino a obrigatoriedade da temática "História e Cultura Afro-Brasileira”, colocam-se como marco legal para práticas de igualdade racial. A primeira previu as contribuições das diferentes culturas e etnias para a formação do povo brasileiro e a educação ambiental como conteúdo curricular obrigatório em todos os níveis de ensino. $\mathrm{O}$ ECA busca assegurar a toda criança o direito de igualdade de condições para a permanência na escola, de ser respeitada pelos educadores, de ter sua identidade e seus valores preservados e de ser posta a salvo de qualquer forma de discriminação, negligência ou tratamento vexatório. A Lei n. ${ }^{\circ}$ 10.639/2003 modificou a Lei n. ${ }^{\circ}$ 9.394/96, que fixa as Diretrizes e Bases da Educação Nacional (LDBEN). Tal mudança estabeleceu a obrigatoriedade do ensino de História e Cultura Afro-Brasileira e Africana nos estabelecimentos de Ensino Fundamental e Médio das escolas brasileiras, oficiais e particulares. Desde sua aprovação, há mais de 10 anos, essa modificação legal busca provocar impacto nestas escolas, no sentido de serem efetivados investimentos na formação de professores e na aquisição de materiais didáticos para trabalhar esse tema. Frente a esse cenário, cabe perguntar: tal impacto atingiu/está atingindo também as escolas de Educação Infantil brasileiras?

Embora a Educação Infantil seja legalmente reconhecida como primeira etapa da educação, a referida modificação na LDBEN não se estendeu às crianças de 0-5 anos. Será que elas foram consideradas muito pequenas para tratar desse tema? Será que as práticas pedagógicas promotoras de igualdade racial na Educação Infantil devem ficar sujeitas à boa vontade da professora ou da escola, em detrimento de um direito legal de todas as crianças? Será que as pedagogias antirracistas não devem compor os currículos da Educação Infantil? Entendemos que, embora tal mudança na LDBEN não tenha se estendido à Educação Infantil, isso não significa que a questão racial tenha ficado fora do currículo dessa etapa da educação. Cabe destacar que a Resolução n. ${ }^{\circ}$, de 17 de dezembro de 2009, que fixa as Diretrizes Curriculares Nacionais para a Educação Infantil (DCNEI), afirma que as diferentes culturas devem ser observadas na organização de propostas pedagógicas na Educação Infantil. Em seu Art. 7o, inciso $\mathrm{V}$, esse documento pretende assegurar que as Propostas Pedagógicas para a Educação Infantil se comprometam com o rompimento das relações de dominação diversas, inclusive étnico-racial. Como será que essas prerrogativas legais vêm funcionando em nossas escolas de Educação Infantil, mais especialmente naquelas que atendem crianças de 0-3 anos? Além disso, no Art. $8^{\circ}$, incisos VIII e IX, as DCNEI determinam que seja garantida às crianças a apropriação das contribuições histórico-culturais dos diferentes povos que constituem a nação brasileira, bem como o combate ao racismo e à discriminação. Como será que tal artigo atravessa as relações entre crianças negras e brancas desde o berçário?

A preocupação por parte do Ministério da Educação (MEC), através de seu departamento específico para a Educação Infantil, no sentido de auxiliar os professores na realização de práticas pedagógicas que contemplem as diferentes culturas já era anterior à aprovação das Diretrizes da Educação Infantil, como da Lei n. ${ }^{\circ} 10.639 / 2003$. Exemplo disso é o Referencial Curricular Nacional para a Educação Infantil (RCNEI), material colocado em circulação em 1998 para atender às determinações da Lei de Diretrizes e Bases da Educação Nacional (Lei n. ${ }^{\circ}$ 9.394/96). A referida lei incluiu, pela primeira 
vez, a Educação Infantil como integrante da Educação Básica e, como decorrência, lançou novos desafios aos profissionais dessa etapa. $\mathrm{O}$ RCNEI foi material organizado em três volumes e integrou a série dos Parâmetros Curriculares Nacionais, elaborados pelo MEC. No que tange aos objetivos gerais para a Educação Infantil, o referido documento aponta que as práticas educacionais devem desenvolver a capacidade de "conhecer algumas manifestações culturais, demonstrando atitudes de interesse, respeito e participação frente a elas e valorizando a diversidade" (Brasil, 1998, v. 1, p. 63). Esse documento também instiga o profissional da Educação Infantil a "assumir um trabalho de acolhimento às diferentes expressões $\mathrm{e}$ manifestações das crianças e suas famílias", valorizando e respeitando a diversidade (Brasil, 1998, v. 1, p. 77). O RCNEI buscou garantir o acolhimento às diferentes culturas, não se limitando apenas a entoar canções, realizar danças típicas ou experimentar pratos típicos em momentos pontuais, por ocasião de determinadas datas comemorativas.

Em 2012, o Instituto Avisa Lá, em uma parceria com o MEC, com o Centro de Estudos das Relações de Trabalho e Desigualdades (CEERT) e com o Núcleo de Estudos Afro-Brasileiros da Universidade de São Carlos, colocou em circulação o material Educação infantil e práticas promotoras de igualdade racial (Silva, Bento, \& Carvalho, 2012), com o propósito de, mais uma vez, apoiar os profissionais da Educação Infantil e as Secretarias de Educação na implementação do Art. $7^{\circ}$, inciso V, das DCNEI. Esse material discute a existência da crença de que a discriminação e o preconceito não fazem parte da rotina das escolas infantis, ou seja, "não há conflitos entre as crianças por conta de seus pertencimentos raciais, [e] que os professores nessa etapa não fazem escolhas com base no fenótipo das crianças" (Instituto
Avisa Lá, 2012, p. 9). Desse modo, ainda se faz necessária uma intervenção qualificada, que reconheça as culturas afro-brasileiras como um componente importante no processo de educação das crianças, e que essa intervenção perpasse as decisões do cotidiano na escola de Educação Infantil.

\section{POR UMA EDUCAÇÃO ANTIRRACISTA NA INFÂNCIA}

Em se tratando de uma educação antirracista para crianças, é imprescindível questionar as maneiras como os brinquedos e as brincadeiras colocados em circulação nos tempos e espaços das creches e pré-escolas produzem a ideia de supremacia de uns em relação aos outros nesse caso, dos brancos sobre os negros.

Através das primeiras interações vividas com seu próprio corpo e com o corpo dos outros - adultos e pares -, as crianças constituem significados relacionados ao patrimônio cultural. Nesse sentido, cabe aos docentes a função de coprodução do currículo, e isso "efetiva-se na construção de um espaço educacional que favoreça, através da interlocução com as crianças e as famílias, experiências nas diferentes linguagens e nas práticas sociais e culturais de cada comunidade" (Richter \& Barbosa, 2010, p. 85).

Dornelles (2006), em pesquisa desenvolvida com crianças de 5 anos que frequentavam uma escola de Educação Infantil de Porto Alegre, observou que, nas suas brincadeiras, as bonecas negras não eram a primeira escolha; contudo, algumas crianças se contentavam com essas, quando não conseguiam pegar as bonecas brancas para brincar. Também a investigação de Amaral (2013) mostra que as crianças de 3-6 anos de uma escola pública de Curitiba/ PR apontam a boneca negra com sendo "feia". Estudos de Marques (2013), produzidos a partir de brincadeiras com bonecas de diferentes tipos de corpos, na Educação 
Infantil, nos mostram que as crianças de 0-5 anos expressavam sentimentos condolentes em relação às bonecas com deficiências físicas ou sensoriais e organizavam brincadeiras de médico ou de hospital para medicalizar e curar o corpo dos brinquedos. As bonecas negras, contudo, provocavam sentimentos de repulsa e, em dados momentos, eram rechaçadas. $\mathrm{O}$ mesmo estudo também mostrou que crianças moradoras de um quilombo localizado perto de uma escola de Educação Infantil da Grande Porto Alegre eram identificadas com as "crianças vindas do Planeta" e a respeito destas circulavam, no ambiente escolar, comentários depreciativos com relação às roupas e aos traços afrodescendentes, como, por exemplo, seu cabelo carapinha, seu cheiro e sua cor de pele (Marques, 2013). Esses preconceitos emergiam nos momentos em que as crianças buscavam um lugar para sentar, um parceiro para dar a mão, conversar ou brincar.

De acordo com Rosenberg (1979), uma das formas de discriminação das pessoas negras está relacionada à associação do negro a personagens antropomorfizadas e a animais. Também os estudos de Amaral (2013) mostram o quanto "imperava na instituição uma valorização da 'branquidade normativa', presente em murais, cartazes, mascote, logomarca que representa a instituição" (p. 212) e no modo, muitas vezes velado, como as professoras expressam suas preferências pelas crianças brancas. Em decorrência de tal valorização, esta pesquisadora identificou certo desconforto expresso pelas crianças negras em relação ao seu pertencimento étnico-racial, de modo a terem, visivelmente, afetadas a sua autoconfiança e autoestima.

As crianças, em casa, nas ruas ou nas escolas de Educação Infantil, não estão alheias a estas percepções em seu cotidiano. Os modos como as pessoas negras aparecem na maioria das imagens apresentadas na mídia, ou seja, como pessoas estética, social e economicamente inferiores aos brancos, têm um "conector histórico”, como explica Sodré (1999). Para esse autor, essas imagens se constituíram historicamente no Brasil, sendo "um signo presente de um passado ausente" (Sodré, 1999, p. 118). Provocando a pensar nessa direção, Dornelles (2006) e Kaercher (2010) destacam a necessidade de se problematizar o modo como questões étnico-raciais vêm sendo apresentadas à infância, pois é importante que se questione não somente a maneira como as crianças interpretam e são afetadas por essas imagens, mas também o modo como as professoras o fazem. Apontam a necessidade de a questão da raça ser trabalhada na formação de professores, abarcando não somente a pesquisa, mas também intervenções, no sentido de transformar a realidade étnico-racial conflitiva na qual as crianças, negras ou não, vêm sendo educadas. A educação antirracista na infância deve passar pela ludicidade e pela qualidade da intervenção do professor. Existem muitos "modos" de subjetivar, e os brinquedos e as brincadeiras são exemplos disso. Dornelles (2003) problematiza a forma como esses "vêm produzindo um tipo de corpo, um gênero, uma raça, uma geração, uma etnia, enfim, sujeitos infantis de um tipo, e não de outro" (p. 18). Desse modo, os brinquedos são artefatos culturais nada inocentes - eles produzem determinados tipos de sujeitos infantis e não outros (Marques, 2013). Isso não pode deixar de ser problematizado aquando da análise cultural infantil contemporânea, tendo em vista os efeitos do poder de compra e das desigualdades sociais que se manifestam

\footnotetext{
${ }^{1}$ Com referência ao filme Planeta dos Macacos, série de filmes de ficção científica produzida nos Estados Unidos, na qual os seres humanos e os macacos se confrontam.
} 
nas infâncias e nas brincadeiras das crianças (Sarmento, 2005).

Espaços, brinquedos e outros materiais didáticos alusivos às culturas afro-brasileiras podem oportunizar às crianças pequenas o prazer do encontro com as diferenças, através de seus sons, cores, sabores, texturas, cheiros, movimentos, brilhos. A criação desses espaços pedagógicos, bem como a produção de outras pedagogias, com suas ações educativas, podem vir a promover uma educação antirracista. Para que "outra" realidade seja construída, é preciso que tal discussão atravesse o cotidiano das escolas de Educação Infantil e a formação dos professores, não só no curso de Pedagogia, mas em qualquer instância de educação das crianças.

\section{As ALAMEDAS DA PESQUISA}

Qual o impacto do Art. $7^{\circ}$, inciso V, das DCNEI nas escolas de Educação Infantil? De que modo as culturas afro-brasileiras vêm sendo apresentadas às crianças de 0-3 anos? Para tentar responder a essas questões, buscamos fazer, durante a pesquisa, um exercício de conversa. Chamamos a atenção para o termo conversa, pois se toma como referência o conceito de Larrosa (2003), quando afirma que "se alguém pode discutir ou dialogar, ou debater, com qualquer um, é claro que não se pode conversar com qualquer um” (p. 212). Então, uma palestra ou um discurso podem ser preparados de antemão, mas uma conversa não. Conversar tem o significado de falar "com" os outros - o que é diferente de falar "para" os outros. Falar "com" os outros requer escuta. Escutar é acolher os pensamentos do outro e deixar que esses provoquem nossos próprios pensamentos. Por isso falamos/conversamos sobre raça com crianças, estudantes de Pedagogia e gestores de escolas.
Apoiadas no pensamento de Larrosa (2003), escolhemos que os rumos sobre o mito do preconceito racial, nessa conversa, seriam construídos na própria conversa. $\mathrm{O}$ propósito foi investigar os modos como a cultura afro-brasileira vem sendo apresentada às crianças, em escolas de Educação Infantil, para implementação do Art. $7^{\circ}$, inciso V, das DCNEI. Tal investigação envolveu 11 escolas da região metropolitana de Porto Alegre, no ano de 2013.

A equipe de investigação contou com a colaboração de um grupo de 14 assistentes de pesquisa, estudantes do curso de Pedagogia, matriculadas na disciplina de Educação Infantil, em uma instituição privada, localizada na região metropolitana de Porto Alegre. Essas estudantes colaboraram nas diferentes etapas da investigação, sendo que, para isso, foram realizados encontros semanais com as pesquisadoras. Nesses encontros foram estudadas as determinações/orientações da Lei n. ${ }^{\circ}$ 10.639/2003 e da Resolução n. ${ }^{\circ}$ 5/2009, bem como discutidos diversos estudos acadêmicos que tratam da racialidade e da educação de crianças de 0-3 anos, entre eles: Amaral (2013), Dornelles (2003, 2006), Kaercher (2010), Marques (2013), Rosenberg (1979), e outros.

Investigaram-se 11 escolas de Educação Infantil que atendem crianças de 0-3 anos, sendo três públicas (EMEI) e oito de iniciativa privada (EEI). Em cada uma dessas instituições, foram entrevistados dois profissionais: uma pessoa representante da gestão e uma professora de Educação Infantil que atua com crianças de 0-3 anos, perfazendo um total de 22 profissionais, todas do sexo feminino (v. Tabela 1).

Sobre a formação dessas profissionais, constatamos que todas as professoras possuíam qualificação para a docência na Educação Infantil, sendo que apenas duas delas possuíam a formação mínima prevista na LDBN para 
TA B EL A 1

Identificação das Participantes

\begin{tabular}{lccc}
\hline $\begin{array}{c}\text { Escolas de educação } \\
\text { infantil }\end{array}$ & Município & $\begin{array}{c}\text { Gestora } \\
\text { Escolar }\end{array}$ & Professora \\
\hline EEI1 & Gravataí & GE1 & P1 \\
EEI2 & Cachoeirinha & GE2 & P2 \\
EEI3 & Cachoeirinha & GE3 & P3 \\
EEI4 & Cachoeirinha & GE4 & P4 \\
EEI5 & Cachoeirinha & GE5 & P5 \\
EMEI6 \\
(pública) & Gravataí & GE6 & P6 \\
EEI7 & Porto Alegre & GE7 & P7 \\
EEI8 & Gravataí & GE8 & P8 \\
EEI9 & Porto Alegre & GE9 & P9 \\
$\begin{array}{l}\text { EMEI10 } \\
\text { (pública) }\end{array}$ & Gravataí & GE10 & P10 \\
$\begin{array}{l}\text { EMEI11 } \\
\text { (pública) }\end{array}$ & Gravataí/RS & GE11 & P11 \\
\hline
\end{tabular}

essa docência, ou seja, o curso de Magistério, em nível médio. No que se refere à formação das gestoras, sete delas eram graduadas em Pedagogia e quatro em Letras e Psicologia.

A metodologia abarcou observações nos espaços escolares e entrevista com uma gestora e uma professora, em cada uma das 11 escolas pesquisadas. Para isso, as pesquisadoras elaboraram, em conjunto com as assistentes de pesquisa, três roteiros semiestruturados contendo tópicos para orientar as observações e as conversas com as professoras e com as gestoras. As questões que constituíram esses instrumentos foram elaboradas tendo como referência os estudos realizados pelo grupo de pesquisadores acerca das legislações brasileiras e de publicações científicas sobre raça e Educação Infantil, estudadas durante os encontros. O primeiro instrumento (v. Tabela 2) foi elaborado com o propósito de documentar as imagens, os materiais e os brinquedos alusivos à cultura africana presentes nos espaços das escolas infantis pesquisadas.

É importante pontuar que as observações nas turmas de Educação Infantil não tiveram o propósito de classificar as crianças conforme categorias predefinidas pela Psicologia do Desenvolvimento (Dahlberg, Moss, \& Pence, 2003, p. 191), mas de entrar com curiosidade no espaço das professoras e das crianças para conhecer o que acontecia (ou não) quando esse tema era tratado, ou seja, como as questões raciais atravessavam o cotidiano de cada Escola Infantil.

$\mathrm{O}$ segundo e o terceiro instrumentos consistiram em um "roteiro de entrevista" com as professoras e gestoras. Contudo, sabíamos que tal roteiro deveria ser tão flexível quanto fosse necessário, de modo a não formalizar a entrevista, mas, ao contrário, criar condições para que ela acontecesse na forma de uma conversa entre pesquisadores, professores e gestores. Os pontos sobre os quais tais conversas transitaram envolveram o Projeto Político Pedagógico (PPP) da escola, 
TAB ELA 2

Roteiro de Observações

\begin{tabular}{|c|c|c|}
\hline Materiais & Identificação do local & $\begin{array}{l}\text { Listagem/ descrição } \\
\text { do material } \\
\text { pedagógico }\end{array}$ \\
\hline \multicolumn{3}{|l|}{$\begin{array}{l}\text { Há imagens de pessoas negras } \\
\text { nas paredes da escola e das salas } \\
\text { de berçários }\end{array}$} \\
\hline $\begin{array}{l}\text { Há bonecos e bonecas negras ou } \\
\text { outros brinquedos que façam } \\
\text { alusão às questões raciais: jogos } \\
\text { de memória, quebra-cabeça, etc. }\end{array}$ & & \\
\hline $\begin{array}{l}\text { Há obras de literatura infantil } \\
\text { que tratam da questão racial }\end{array}$ & & \\
\hline $\begin{array}{l}\text { Há CDs ou DVDs que tratem da } \\
\text { cultura Afro-brasileira }\end{array}$ & & \\
\hline
\end{tabular}

TAB EL A 3

Roteiro Semiestruturado da Entrevista com Gestoras

A escola possui PPP? O que consta nesse documento sobre questões raciais? (solicitar para ver o PPP da escola)

Existem problemas raciais na escola? Relate situações e pessoas envolvidas

A escola tem desenvolvido ações para promover a igualdade racial? Quais? Quando? Quais pessoas são envolvidas? Que documentos e/ou materiais fundamentam essas ações? Quais resultados foram observados?

Essa escola já trabalhou as DCNEI com seu grupo de professores? Quando e de que modo isso foi realizado? Como foi abordado/discutido o Art. 7, inciso V, que trata das relações étnico-raciais?

A escola conta com materiais para trabalhar essa temática? Quais? Onde costumam ficar guardados? (se possivel, fotografar esses materiais)

Que dificuldades são encontradas no que tange a implementação do Art. 7, inciso V, das DCNEI?

as Diretrizes Curriculares Nacionais para a Educação Infantil, os planejamentos e os materiais que usavam para tratar desse tema com as crianças, bem como as dificuldades que encontravam para implementar, ou não, o Art. $7^{\circ}$, inciso V, das DCNEI (v. Tabelas 3 e 4).

Os momentos de observação e de entrevistas foram agendados anteriormente com as participantes, conforme a disponibilidade de tempo de cada uma. Elas receberam as informações necessárias sobre a pesquisa e oficializaram sua participação mediante assinatura do Termo de Consentimento Livre Esclarecido (TCLE). Despois de cumpridas as exigências éticas para realização de pesquisa com seres humanos, foram aplicados os instrumentos de pesquisa. As observações foram fotografadas e registradas em um caderno de campo, mediante autorização prévia para uso de imagens, concedida por escrito pela direção das escolas. As entrevistas com as gestoras e professoras foram gravadas e 
TAB ELA 4

Roteiro Semiestruturado da Entrevista com Professoras

Existem problemas raciais na escola? Relate situações e pessoas envolvidas

Você se sente preparada para desenvolver ações promotoras de igualdade racial? Questões raciais perpassam o seu planejamento? Quais? Em que momentos? Que documentos e/ou materiais fundamentam legalmente e teoricamente suas ações?

Você conhece as DCNEI? Quando e de que modo se apropriou desse documento? Como foi abordado/discutido o Art. 7, inciso V, que trata das relações étnico-raciais?

A escola conta com materiais para trabalhar essa temática? Quais? Onde costumam ficar guardados? (se possível, fotografar esses materiais)

Você observa alguma curiosidade ou preferência racial entre as crianças de sua turma? (relatar)

É possível implementar práticas pedagógicas promotoras de igualdade racial com as crianças $0-3$ anos? Já trabalhou essa temática? Relate uma ou mais prática/s antirracista/s que você tenha proposto em suas aulas. Em que momento essa prática aconteceu? Em que lugar? Que materiais foram usados (livros, jogos, brinquedos, música, objetos, etc.)?

Que dificuldades são encontradas no que tange a implementação do Art. 7, inciso V, das DCNEI?

depois transcritas pelas assistentes de pesquisa.

As pesquisadoras reuniram-se semanalmente com as assistentes de pesquisa para tratamento das informações. Os dados produzidos foram articulados com os documentos organizados pelo MEC que tratam dessa temática - entre eles, DCNEI (2009), RCNEI (Brasil, 1998) e Práticas Promotoras de Igualdade Racial - e com estudos publicados por pesquisadores no campo da educação de bebês no contexto escolar e de questões raciais - entre eles: Amaral (2013), Dias (2012), Dornelles (2003, 2006), Gomes (2005, 2012), Hall (2003), Kaercher (2010), Marques (2013), Martins (2009), Oliveira e Abramowicz (2010), Sarmento (2005), Sarmento, Fernandes, e Tomás (2007), dentre outros.

A partir dessa articulação, emergiram três categorias que nos pareceram indissociáveis e, por isso, serão apresentadas/discutidas em conjunto: a invisibilidade do PPP, o silêncio nas rotinas e o vazio nos espaços.

4. A invisibilidade do Projeto Político Pedagógico, o Silêncio NAS ROTINAS E O VAZIO NOS ESPAÇOS:
ACHADOS DESSA/NESSA PESQUISA SOBRE AS QUESTÕES RACIAIS NOS B E RÇÁR I O S

Tendo em vista que as DCNEI orientam que as propostas pedagógicas das escolas de Educação Infantil contemplem as questões raciais, como apontamos desde o início, entendemos como importante investigar o que consta nos PPPs das escolas sobre as mesmas. Contudo, de modo geral, as assistentes de pesquisa encontraram dificuldade em acessar esse documento nas escolas investigadas. As gestoras das 11 escolas afirmaram que suas instituições possuem PPP, mas apenas duas possibilitaram o acesso direto ao documento, que deveria estar ao alcance de toda a comunidade escolar. Entre as justificativas apresentadas pelas gestoras das demais escolas para não disponibilizarem seu PPP, estava o fato de que o documento se encontrava em processo de elaboração.

Em um desses projetos constatamos que a escola se compromete em "trabalhar a realidade cultural e social na vida cotidiana" (EEI3), contudo não está claro nessa proposta qual a 
realidade social e cultural que será trabalhada. Consideramos ser comum que se encontrem, nos espaços escolares, famílias e crianças de diferentes realidades sociais e culturais. No Projeto da outra escola (EMEI6), que faz referência às questões raciais, encontramos de forma mais explícita o compromisso com o rompimento de relações de dominação etária, socioeconômica, étnico-racial, de gênero, regional, linguística e religiosa. Esse compromisso assumido pela escola, através de seu PPP, mostra um diálogo estreito com as DCNEI. No entanto, é importante considerar que, para fazer uma análise mais completa, ainda seria necessário conhecer mais detalhadamente a forma como se deu o processo de elaboração desse documento escolar, ou seja, quem foram as pessoas que atuaram na organização e os modos como estiveram envolvidas em sua construção. Ainda cabe colocar em suspenso a ideia de que este efetivamente oriente as práticas que acontecem no cotidiano da escola, considerando que a professora que atua na referida escola não conhece tal documento. Assim, estamos querendo dizer da importância de essa temática estar contemplada no PPP da escola, mas esse dado é insuficiente para afirmar que naquele espaço estejam sendo implantadas as DCNEI.

Conforme o Art. $12^{\circ}$ da LDBEN, "os estabelecimentos de ensino, respeitando as normas comuns e as do seu sistema de ensino, terão a incumbência de elaborar e executar sua proposta pedagógica”. Essa elaboração requer um trabalho coletivo envolvendo gestores, professores, funcionários, pais e representantes da comunidade; enfim, é um documento que resulta de um processo de gestão democrática e mostra a identidade da escola, ou seja:

Ele revela seu contexto, sua história, seus sonhos, seus desejos, suas crenças, seus valores, suas concepções e, a partir disso, os princípios e as diretrizes que orientam sua ação de educar as crianças e cuidar delas. Revela suas formas de organização, planejamento, avaliação, suas articulações, suas dificuldades, seus problemas e a forma de superá-los, uma vez que o processo de constituição de identidades é dinâmico, a proposta pedagógica de uma instituição está sempre num movimento de construção e reconstrução. (Lopes, Mendes, \& Faria, 2006, p. 13)

Nesse sentido, a pesquisa mostrou que a elaboração desse documento, que está sempre em um movimento de reconstrução, também vem servindo de subterfúgio para a não consolidação desse trabalho nas escolas, considerando que, como foi dito anteriormente, somente duas escolas apresentaram seus Projetos Político Pedagógicos. Entre outras coisas, isso sinaliza que a instituição ainda não tem bem claro quais são os seus sonhos, os seus desejos, as suas concepções, os seus caminhos, os seus desafios, etc., pois, segundo Libâneo, Toschi, e Oliveira (2005), o Projeto Pedagógico é um documento que "propõe uma direção política e pedagógica para o trabalho escolar, formula metas, prevê as ações, institui procedimentos e instrumentos de ação" (p. 345). Embora as representantes da gestão afirmem que suas escolas possuem um PPP, esse documento encontra-se invisível à comunidade escolar.

Ainda com relação às DCNEI, documento elaborado pelo MEC, que deveria orientar a construção dos PPP, somente três gestoras entrevistadas afirmaram conhecer e já terem trabalhado com esse material em reuniões pedagógicas (GE1, GE4 e GE5). As demais não conhecem ou não souberam responder. Uma das gestoras, que é graduada em Psicologia (GE7), afirmou não ver necessidade de trabalhar as DCNEI com seu grupo de professoras. Outra afirmou ter estudado esse 
material durante o seu curso de graduação. Analisando os dados coletados junto às professoras e às gestoras, temos um cenário que questiona o efetivo funcionamento, nas escolas, das leis vigentes. Das 22 profissionais entrevistadas, apenas sete (GE1, GE4, GE5, P1, $\mathrm{P} 5, \mathrm{P} 8, \mathrm{P} 11)$ afirmaram conhecer as DCNEI, documento que deveria orientar a construção das propostas pedagógicas das escolas onde atuam. Conhecer esse e outros documentos, tais como a Lei de Diretrizes e Bases da Educação Nacional (1996) e o Estatuto da Criança e do Adolescente (1990), é, ou deveria ser, um mote para a problematização das questões raciais que atravessam as rotinas e os espaços da Educação Infantil no país.

Com relação à segunda categoria, ou seja, o silenciamento das questões raciais nas rotinas das escolas pesquisadas, as gestoras e as professoras entrevistadas afirmaram que não há necessidade de tratar desse tema porque não existem problemas raciais em suas instituições. Apenas uma das gestoras relatou que, certa vez, "no banheiro, as crianças passavam a toalhinha em um colega negro para limpar a cor dele" (GE5). Reconhecer que existe racismo no cotidiano das escolas é, segundo Gomes (2005), "um ponto importante porque rompe com a hipocrisia da nossa sociedade diante da situação da população negra e mestiça desse país e exige um posicionamento dos(as) educadores(as)" (p. 147).

$\mathrm{O}$ fato de as crianças serem pequenas foi o principal argumento apresentado para o silenciamento das questões raciais no dia a dia da escola infantil, como podemos ver: “as crianças não fazem discriminação porque ainda não entendem" (P7); “as crianças são pequenas e não têm noção de diversidade" (P2); e "os pequenos ainda não têm muita noção do que são preconceitos, os maiores é que, muitas vezes, são influenciados pelos pais e trazem um pouco de preconceitos sobre negro, sobre diferente, etc." (P6). Todavia, segundo Oliveira e Abramowicz (2010),

as crianças nessa faixa etária já conseguem apresentar uma percepção das diferenças raciais, podendo, a partir dessa idade, começar a cristalizar determinadas atitudes com sentido preconceituoso em relação aos que diferem de suas características físicas, evidenciando a necessidade de se iniciar uma intervenção pedagógica que vise à destituição desse tipo de atitude em relação aos colegas. (p. 212)

Outro argumento também usado pelas gestoras foi a quase ausência de crianças negras na escola, ou seja, "esse trabalho não precisa ser feito todo o tempo, pois não há muitos alunos negros na escola. Temos no máximo quatro" (GE2). Tal pensamento evidencia o equívoco de que a história e as culturas africanas digam respeito exclusivamente às pessoas negras.

É necessário que se tenha cuidado para com a recorrência da ideia de infância associada à felicidade e à puerilidade, bem como sobre o equívoco de que a discriminação e o preconceito não fazem parte do cotidiano da Educação Infantil (Instituto Avisa Lá, 2012). Ou seja, de que não há conflitos entre as crianças por conta de seus pertencimentos raciais e de que os professores, nessa etapa, não fazem escolhas com base no fenótipo das crianças. As crianças da escola de Educação Infantil não vivem em redomas protegidas de qualquer tipo de preconceito. Com relação às práticas racistas manifestas pelos professores junto a crianças de 0-2 anos, a pesquisa desenvolvida por Oliveira e Abramowicz (2010) mostra que "os bebês negros são menos 'paparicados' pelas professoras do que os bebês brancos. Ou seja, o racismo, na pequena infância, incide diretamente sobre o corpo, na maneira pela qual ele é construído, acariciado ou repugnado" (p. 222). 
No que se refere a ações antirracistas no dia a dia das escolas, as gestoras entrevistadas afirmaram que promovem essas ações e apontaram os dias 13 de maio ${ }^{2}$ e 20 de novembro ${ }^{3}$ como os momentos em que elas acontecem. Somente uma dessas gestoras (GE3) afirmou que tais ações ocorrem no cotidiano. Ao serem indagadas sobre quais documentos orientam essas ações, nenhum dos referidos foi elencado por elas. Entre as professoras, apenas P6 e P8 afirmaram já ter desenvolvido práticas relacionadas ao tema em questão. Nesse sentido,

torna-se necessário refletir até que ponto as culturas oriundas dos grupos subordinados na sociedade, cujas contribuições não são consideradas como tradição e passado significativo e, por isso, são invisibilizadas e minimizadas nos currículos, poderão vir a ser objeto de investigação e constituir-se na prática educativa dos professores. (Silva, 2005, p. 21)

As demais professoras, durante as entrevistas, pontuaram a pouca idade das crianças - por exemplo: "os alunos são muito pequenos e ainda não têm compreensão sobre desigualdade" (P2); "só trabalho animais e músicas, porque elas são muito pequenas e não têm preferência racial" (P7); e "acredito que se fosse trabalhar seria bem difícil, devido ao fato de elas não pararem mais de 10 minutos em cada atividade" (P6). Tais argumentos das professoras comprovam aquilo que aponta Barbosa (2010), quando problematiza o modo como as crianças são descritas e definidas, ou seja, a partir de suas fragilidades, incapacidades e imaturidade.

Com relação às questões raciais, este estudo mostrou que predomina o silêncio na rotina dos berçários, ou seja, pouco se diz e pouco se faz sobre raça com as crianças de 0-3 anos.

Ainda chamou atenção o fato de a professora (P11) afirmar não contemplar esse tema em seus planejamentos diários, argumentando não ter alunos negros. Essa justificativa desconsidera que viver experiências relacionadas a diferentes culturas, além de uma determinação legal, é um direito de todas as crianças, sendo um equívoco acreditar que a ausência de pessoas negras em uma instituição a exime de incluir diferenças raciais em seu currículo. Afinal, as escolas estão inseridas em um contexto muito maior do que elas mesmas e, desse modo, não se pode pensar as relações raciais fora do conjunto das relações sociais (Gomes, 2005, p. 147). Por fim, ao serem indagadas sobre a existência de alguma dificuldade para abordar esse tema nas escolas, as gestoras entrevistadas afirmaram não existir qualquer problema nesse sentido. Entre as professoras, somente duas delas apontaram dificuldades para tratar desse tema na Educação Infantil, fazendo, mais uma vez, referência à idade das crianças, ou seja, "eles [bebês] não se comunicam, dificultando a troca entre professor-aluno e aluno-aluno, mas acredito que a partir dos 4 anos eles já tenham uma compreensão maior" (P6). Será que os bebês precisam crescer para se comunicar e para serem escutados? Tal discurso da professora mostra o desconhecimento acerca das múltiplas linguagens que os bebês dominam, e sua postura faz jus à preocupação do Ministério da Educação, expressa nas DCNEI, em priorizar as discussões sobre como orientar o trabalho junto às crianças de até 3 anos em creches.

Com relação à terceira categoria, o vazio nos espaços, o estudo mostrou que as paredes das escolas e as salas de aula estão, praticamente,

\footnotetext{
${ }^{2}$ Data em que se comemora o Dia Nacional da Abolição da Escravatura no Brasil.

${ }^{3}$ Data em que se comemora o Dia Nacional da Consciência Negra.
} 
vazias de imagens e materiais pedagógicos alusivos à cultura afro-brasileira. Somente quatro gestoras (G2, G5, G8 e G10) afirmaram que suas escolas possuem materiais pedagógicos para desenvolver trabalhos relacionados às diferenças raciais, entre eles, fantoches $\mathrm{e}$ livros. Contudo, assim como ocorreu com os PPPs, as assistentes de pesquisa não tiveram acesso a esses materiais, pois, segundo as gestoras, estes se encontravam guardados na secretaria, no depósito, na biblioteca e/ou na sala de Psicologia. As profissionais também não souberam listar os títulos das obras de literatura infantil que versam sobre esse tema que a escola possui. As professoras afirmaram que possuem materiais didáticos e citaram as bonecas, os fantoches, figuras de pessoas negras e o livro Menina Bonita do Laço de Fita $^{4}$, de Ana Maria Machado.

Vemos aqui que tanto as professoras como as gestoras possuem um repertório bastante restrito no que se refere à literatura infantil que versa sobre esse tema, de modo que somente uma obra foi nomeada por elas. Temos hoje, no Brasil, materiais ricos que tratam desse tema; contudo, ainda circulam pouco nas escolas.

Outra professora apontou "falta de recursos" (P11) como dificuldade em trabalhar o tema na sua turma. Destaca-se, contudo, que essa escola integra a rede pública, sendo que cabe às Secretarias de Educação a responsabilidade em prover os recursos necessários. Sobre isso, resta indagar se essa escola tem solicitado tais materiais junto à Secretaria, pois muitas escolas brasileiras, mesmo tendo recebido o material do MEC, mantêm-nos em caixas fechadas, abrindo, às vezes, por solicitação dos professores ou em datas comemorativas.

Entendemos que uma Educação Infantil antirracista requer, primeiramente, que se reconheça que existe discriminação racial na sociedade brasileira e que está presente nas diferentes etapas da Educação Básica, inclusive nos berçários. Em se tratando da educação das crianças pequenas, os PPPs das escolas precisam ser alinhados com as DCNEI, naquilo que recomendam em relação às questões raciais, no Art. $7^{\circ}$, inciso $\mathrm{V}$. O rompimento do mito da ausência de preconceito racial na Educação Infantil requer que se problematize a invisibilidade dos PPPs das escolas, o silêncio nas rotinas e o vazio de referências afrobrasileiras nos espaços escolares.

\section{ALINHAVOS FINAIS DESA P E S Q U IS A}

O mito da ausência de preconceito racial continua presente nas escolas de Educação Infantil no Brasil. As novas legislações e os documentos importantes colocados em circulação pelo Ministério de Educação ainda estão invisíveis nos Projetos Político Pedagógicos das escolas, sendo que as DCNEI são pouco conhecidas e discutidas em reuniões pedagógicas pelos gestores e professores que atuam com crianças de 0-3 anos. A maioria das escolas pesquisadas não consolidou seu PPP, comprometendo não só a identidade, mas também a direção política e pedagógica da instituição, como alertam os estudos de Libâneo, Toschi, e Oliveira (2005) e de Lopes et al. (2006). Diversas professoras e gestoras participantes da pesquisa ainda possuem uma concepção de infância e de criança que deve ser problematizada, considerando os estudos de Barbosa (2010), Gomes (2005), Sarmento (2005), Sarmento et al. (2007), quando afirmam as crianças como sujeitos históricos, culturais e de direitos. Durante as conversas,

${ }^{1}$ A história tem como personagem principal uma linda menina negra que usa laços de fita no cabelo. Essa personagem é admirada por um coelhinho branco que deseja ter uma filha tão linda quanto ela. O enredo se dá a partir de uma sequência de episódios engraçados nos quais o coelho tenta descobrir o segredo de como ter a pele escura. 
disseram mais sobre as coisas que os bebês não são e não fazem do que sobre aquilo que eles expressam nas rotinas e espaços da escola. A partir disso, negam a ocorrência de qualquer tipo de preconceito racial na Educação Infantil e afirmam que as crianças não têm "noção" de diferença racial, desconsiderando estudos diversos - entre eles, Amaral (2013), Dornelles (2003, 2006), Kaercher (2010), Marques (2013), Sodré (1999) - que mostram o quanto as crianças estão atentas às diferenças raciais.

As observações também mostraram um silêncio na rotina e um vazio nos espaços. Quando falamos em "silêncio na rotina", estamos nos referindo à ausência de conversas, músicas e histórias alusivas à cultura africana e afro-brasileira no dia a dia dos bebês e crianças pequenas. Os dados mostraram que as culturas de matriz africana invadem a rotina das escolas somente em momentos pontuais, como o Dia da Abolição da Escravatura e a Semana da Consciência Negra, contribuindo para disseminar e fortalecer a ideia de que são culturas exóticas. Com relação ao vazio no espaço, estamos fazendo referência à falta de lugar para que as crianças negras se vejam representadas nas imagens expostas nas paredes, nos livros infantis, nos brinquedos e em outros materiais pedagógicos presentes na escola. Ao tratarmos de uma educação antirracista desde os bebês, falamos em criança cidadã e não defendemos somente seus direitos de pertença a uma determinada comunidade, mas sim, como sugerem Sarmento et al. (2007), que as crianças negras usufruam de seus direitos civis, políticos, culturais e de natureza social. Enfim, tratamos de uma Educação Infantil que ainda carece de investimentos em recursos físicos, materiais e na formação de professores para que se possa avançar na concretização do Art. $7^{\circ}$, inciso V, das Diretrizes Curriculares Nacionais para a Educação Infantil.
Este foi um estudo pontual e localizado sobre o mito da ausência de preconceito racial na Educação Infantil brasileira. Retomálo em outros lugares e em outros momentos é necessário para que se possa fazer ecoar, na formação de professores e nas escolas de Educação Infantil, as histórias e as culturas das famílias de tantas crianças brasileiras.

Observamos que o mito da ausência do preconceito, que se apresenta nas escolas investigadas, acaba desautorizando uma gama muito grande de diferenças culturais que atravessam a educação desde os bebês, tendo em vista que as identidades negras são constituídas em meio a relações de poder e de hierarquias. Assim encerramos, por ora, nossa conversa, com o desejo de "imaginar o ato de educar como uma colocação, à disposição do outro, de tudo aquilo que o possibilite ser distinto do que é, em algum aspecto. Uma educação que aposte transitar por um itinerário plural, criativo, sem regras rígidas que definam os horizontes de possibilidades" (Duschatzky \& Skliar, 2001, p. 119), tendo em vista que o outro é o outro e só. 


\section{REFERÊ NCIAS}

Amaral, A. C. T. (2013). A infância pequena e a construção da identidade étnico-racial na educação infantil (Tese de Doutorado). Faculdade de Educação da Universidade Federal do Paraná, Curitiba, PR, Brasil.

Barbosa, M. C. S. (2010). As especificidades da ação pedagógica com os bebês. Brasília, DF, Brasil: MEC/Secretaria de Educação Básica.

Brasil. Ministério da Educação e do Desporto. Secretaria de Educação Fundamental. (1998). Referencial Curricular Nacional para Educação Infantil. Brasília, DF, Brasil: MEC/ SEF.

Dahlberg, G., Moss, P., \& Pence, A. (2003). Qualidade na educação da primeira infância: Perspectivas pós-modernas. Porto Alegre: Artmed.

Dias, L. R. (2012). Formação de professores, educação infantil e diversidade étnicoracial: Saberes e fazeres nesse processo. Revista Brasileira de Educação, 17(51), 661749.

Dornelles, L. V. (2003). O brincar e a produção do sujeito infantil. Pátio: Educação Infantil, 1(3), 17-20.

Dornelles, L. V. (2006). Existe fada negra? Pátio: Educação Infantil, 4(10), 17-20.

Duschatzky, S., \& Skliar, C. (2001). O nome dos outros. Narrando a alteridade na cultura e na educação. In J. Larrosa \& C. Skliar (Orgs.), Habitantes de Babel: Políticas e poéticas da diferença (pp. 119-138). Belo Horizonte: Autêntica.

Foucault, M. (1987). Vigiar e punir: História da violência nas prisões. Petrópolis: Vozes.

Gomes, N. L. (2005). Educação e relações raciais: Refletindo sobre algumas estratégias de atuação. In K. Munanga (Org.), Superando o racismo na escola (2a ed., pp. 143-154). Brasília: Ministério da Educação, Secretaria de Educação Continuada, Alfabetização e
Diversidade.

Gomes, N. L. (2012). Movimento Negro e educação: Ressignificando e politizando a raça. Educação \& Sociedade, 33(120), 727744.

Hall, S. (2003). Da diáspora: Identidades e mediações culturais. Belo Horizonte: Ed. da Universidade Federal de Minas Gerais, e Brasília: UNESCO no Brasil.

Instituto Avisa Lá. (2012). Educação infantil e práticas promotoras de igualdade racial. São Paulo, Brasil: Centro de Estudos das Relações de Trabalho e Desigualdades. Recuperado de https://www.avisala. org.br/wp-content/uploads/2015/06/ revistadeeducacaoinfantil 2012.pdf

Kaercher, G. E. P. S. (2010). Pedagogias da racialização ou dos modos como se aprende a "ter" raça e/ou cor. In M. I. E. Bujes (Org.), Pedagogia sem fronteiras (pp. 85-91). Canoas: Eulbra.

Larrosa, J. (2003). A arte da conversa. In C. Skliar (Ed.), Pedagogia (improvável) da diferença. E se o outro não estivesse aí? (pp. 211-216). Rio de Janeiro: DP\&A.

Libâneo, J. C., Toschi, M. S., \& Oliveira, J. F. (2005). Educação escolar: Políticas, estrutura e organização (2a Ed.). São Paulo: Cortez Editora.

Lopes, K. R., Mendes, R. P., \& Faria, V. L. B. (Orgs.). (2006). Proinfantil (Coleção Proinfantil, Módulo III, Unidade 4). Brasília: MEC, Secretaria de Educação Básica, Secretaria de Educação a Distância.

Marques, C. M. (2013). Experiência com bonecas anormais no curso de pedagogia: Construindo modos de ser professora (Tese de Doutorado). Faculdade de Educação da Universidade Federal do Rio Grande do Sul, Porto Alegre, Brasil.

Martins, C. (2009). Negro, publicidade e o ideal de branqueamento da sociedade brasileira. Rumores, 3(5). doi:10.11606/issn.1982- 


\section{X.rum.2009.51157}

Oliveira, F., \& Abramowicz, A. (2010). Infância, raça e "paparicação". Educação em Revista, 26(2), 209-226. doi:10.1590/S010246982010000200010

Richter, S., \& Barbosa, M. (2010). Os bebês interrogam o currículo: As múltiplas linguagens na creche. Educação, 1(1), 85-96. doi:10.5902/198464441605

Rosenberg, F. (1979). Discriminações éticoraciais naliteratura infanto-juvenil brasileira. Revista Brasileira de Biblioteconomia, 12(3/4), 155-166. doi:1979-0000005-00001

Sarmento, M. J. (2005). Gerações e alteridade: Interrogações a partir da sociologia da infância. Educação \& Sociedade, 26(91), 361-378. doi:10.1590/S0101$\underline{73302005000200003}$

Sarmento, M. J., Fernandes, N., \& Tomás, C. (2007). Políticas públicas e participação infantil. Educação, Sociedade \& Culturas, 25, 183-206.

Silva, A. C. (2005). A desconstrução da discriminação no livro didático. In $\mathrm{K}$. Munanga (Org.), Superando o racismo na escola (2a ed., pp. 21-37). Brasília: Ministério da Educação, Secretaria de Educação Continuada, Alfabetização e Diversidade.

Silva Jr, H., Bento, M. A. S., \& Carvalho, S. P. (Coords.). (2012). Educação infantil e práticas promotoras de igualdade racial. São Paulo: Centro de Estudos das Relações de Trabalho e Desigualdades - CEERT e Instituto Avisa Lá - Formação Continuada de Educadores.

Sodré, M. (1999). Claros e escuros: Identidade, povo e mídia no Brasil. Petrópolis: Vozes.

\section{LEGISLAÇÃ O CONSULTADA}

Constituição da República Federativa do Brasil de 1988. Brasília, DF, Brasil.

Lei n. ${ }^{\circ}$ 8.069, de 13 de julho de 1990. Dispõe sobre a proteção integral à criança e ao adolescente. Brasília, DF, B r asil. Recuperado em $16 \quad$ junho, 2017 , de http://www.conselhodacrianca.al.gov.br/ sala-de-imprensa/publicacoes/ECA\%20 ATUALIZADO.pdf/view

Lei n. ${ }^{\circ}$ 9.394, de 20 de dezembro de 1996. Estabelece as Diretrizes e Bases da Educação Nacional. Ministério da Educação. Brasília, DF, Brasil. Recuperado em 16 junho, 2017, de http://www.planalto.gov.br/ccivil 03/leis/ L9394.htm

Lei n. ${ }^{\circ} 10.639$, de 9 de janeiro de 2003. Altera a Lei n. ${ }^{\circ}$ 9.394, de 20 de dezembro de 1996, que estabelece as Diretrizes e Bases da Educação Nacional, para incluir no currículo oficial da Rede de Ensino a obrigatoriedade da temática "História e Cultura Afro-Brasileira", e dá outras providências. Brasília, DF, Brasil. Recuperado em 10 junho, 2017, de http://www.planalto. gov.br/ccivil 03/leis/2003/L10.639.htm 
THE MYTH OF THE ABSENCE OF RACIAL PREJUDICE IN EARLY CHILDHOOD EDUCATION IN BRAZIL

\section{Abstract}

This paper addresses the racial prejudice in Early Childhood Education and is the result of a qualitative investigation in kindergarten schools of the metropolitan region of Porto Alegre, in 2013. It was designed to investigate how African cultures are presented to 0-3 year old children aiming to instill the Art. 7th, paragraph V, from the NationalCurricular Guidelines for Children's Education (DCNEI in Brazil). According to this document, pedagogical proposals must be compromised with breaking several types of relations of domination, including ethnical and racial ones. Data collection was conducted with observations and conversation with managers and teachers working in kindergarten schools. The results showed that most teachers and managers do not know the DCNEI. These practitioners stated that racial issues do not occur in Early Childhood Education and justified that 0-3 year old children are small and do not note such differences. Practically, there are no didactic materials and images of black people in the spaces of the investigated schools. Finally, there is a need not only to give visibility to 0-3 year old children, but also to deconstruct the myth of the lack of racial prejudice, inasmuch as African histories and cultures may enter in times and spaces of the kindergarten schools.

Keywords: Early Childhood Education; National Curricular Guidelines for Children's Education; Racial prejudice
EL MITO DE LA AUSENCIA DE PREJUICIO RACIAL EN LA EDUCACIÓN IN FA NTIL EN BRASIL

\section{RESUMEN}

Este artículo habla del prejuicio racial en la Educación Infantil y resultó de una pesquisa cualitativa realizada en escuelas infantiles de la región metropolitana de Porto Alegre, en 2013. Tuvo el propósito de investigar el modo como las culturas africanas son presentadas a los niños de 0-3 años en el sentido de implantar el Art. $7^{\circ}$, inciso V, de las Directrices Curriculares Nacionales para la Educación Infantil (DCNEI). Según ese documento, las propuestas pedagógicas deben estar comprometidas con el rompimiento de las relaciones de dominación diversas, incluso étnicas y raciales. La colecta de datos se dio por medio de observaciones y de conversaciones con gestores y maestros que actúan en escuelas infantiles. Los resultados mostraron que la mayoría de los profesionales desconoce las DCNEI. Estos afirmaron que no ocurren problemas raciales en la Educación Infantil y justificaron que los niños de 0-3 años son pequeños y no perciben tales diferencias. Prácticamente, no hay materiales didácticos e imágenes de personas negras en los espacios de las escuelas pesquisadas. En fin, es preciso no solo dar visibilidad a los niños de 0-3 años como también deshacer el mito de la ausencia de prejuicio racial para que las historias y culturas africanas adentren en los tiempos y espacios de estas escuelas.

Palabras Clave: Educación Infantil; Directrices Curriculares Nacionales para la Educación Infantil; Prejuicio racial

\footnotetext{
${ }^{\text {I }}$ Universidade Alto Vale do Rio do Peixe (UNIARP/SC) e Universidade Comunitária da Região de Chapecó-SC, Programa da Pós-Graduação. ORCID: 0000-0002-2137-4760

"I Universidade Federal do Rio Grande do Sul (UFRGS), Faculdade de Educação. ORCID: 0000-0001-7130-9513
} 